\title{
MELAS: a new disease associated mitochondrial DNA mutation and evidence for further genetic heterogeneity
}

\author{
M G Hanna, I P Nelson, J A Morgan-Hughes, N W Wood
}

\begin{abstract}
Objectives-To define the molecular genetic basis of the MELAS phenotype in five patients without any known mutation of mitochondrial DNA.

Methods-Systematic automated mitochondrial DNA sequencing of all mitochondrial transfer RNA and cytochrome c oxidase genes was undertaken in five patients who had the MELAS phenotype. Results- A novel heteroplasmic mitochondrial DNA mutation was identified in the transfer RNA gene for phenylalanine in one case (patient 3 ). This mutation was not detected in the patient's blood or in her mother's blood. No pathogenic mutations were identified in the other four patients.

Conclusions-This is the first point mutation in the transfer RNA gene for phenylalanine to be associated with MELAS. The absence of mutations in the remaining four patients suggests that there is further genetic heterogeneity associated with this mitochondrial phenotype.

(F Neurol Neurosurg Psychiatry 1998;65:512-517)
\end{abstract}

Keywords: MELAS; mitochondrial DNA; tRNA gene

The first description of a disorder which included stroke-like episodes, lactic acidaemia, and ragged red fibres was by Shapira et al in 1975. ${ }^{1}$ Pavlakis et al described further cases, introduced the acronym MELAS (mitochondrial encephalomyopathy with lactic acidosis and stroke-like episodes), and suggested that this represented a distinct mitochondrial disease phenotype. Subsequent reports have established the central role of mitochondrial respiratory chain dysfunction in the pathogenesis of this disorder. ${ }^{34}$ In 1990 Goto et al. ${ }^{5}$ identified a point mutation in the transfer RNA (tRNA) leucine(UUR) gene in some patients with MELAS. This has now been established to be the commonest mitochondrial DNA (mtDNA) defect described in association with MELAS although it is not specific to the MELAS phenotype. ${ }^{6}$ Subsequent studies have identified additional point mutations indicating that MELAS is a genetically heterogeneous disorder. ${ }^{7}$ However, there remains a group of patients with typical stroke-like episodes, ragged red fibres on muscle biopsy, and lactic acidaemia who do not harbour any of the known defects of mitochondrial DNA. We have analysed mtDNA in five such patients and in one of them have identified a novel heteroplasmic mtDNA tRNA gene point mutation.

\section{Patients and methods}

PATIENT 1

A 30 year old woman was a normal full term delivery and had normal motor and cognitive milestones. At the age of 23 years, over the course of a few days, she developed a left hemiparesis headache, nausea, and vomiting culminating in a generalised seizure. Examination showed a left homonymous hemianopia and mild left sided pyramidal weakness. A right occipitotemporal high signal area was seen on T2 weighted MRI consistent with an area of infarction but not conforming to a single vascular territory. Plasma lactate was raised at $4.1 \mathrm{mmol} / 1$ (normal <1.6). Nerve conduction studies showed changes consistent with a subclinical sensory axonal neuropathy but EMG was normal. Muscle biopsy showed that $10 \%$ of fibres were ragged red with the succinate dehydrogenase (SDH) stain. All the ragged red fibres (RRFs) were cytochrome c oxidase (COX) positive. The patient had no further stroke-like episodes but developed epilepsia partialis continua of her left arm resistant to treatment with anticonvulsant drugs. Examination at the age of 30 years showed a left homonymous hemianopia and some limitation of eye movements in all directions consistent with a mild external ophthalmoplegia, but with no ptosis. There was horizontal gaze evoked nystagmus in both directions of gaze and she had a persistent no-no head tremor. The left hand was held flexed at the wrist and there was some clawing. There was rhythmic flexion or extension jerking of the left wrist which on EEG back averaging was shown to have a clear cortical correlate. There was no limb weakness and the rest of the examination was normal. There was no family history of neurological disease.

\section{PATIENT 2}

This left handed man developed sensorineural deafness in childhood but was otherwise well until the age of 52 when over the course of a few days he developed headaches, nausea, vomiting, and an unsteady gait with a tendency to veer to the left. This culminated in left focal motor seizures affecting his arm and leg. Examination showed a mild left hemiparesis. Brain CT showed a low density area in the right parietal lobe consistent with an area of infarction. He made an initial recovery then represented three weeks later with a sudden 
increase in weakness of his left side followed by left focal motor seizures. He became confused and drowsy and an EEG was consistent with non-convulsive epileptic status. Plasma lactate was raised at $7.49 \mathrm{mmol} / 1$. T2 weighted brain MRI showed high signal bilaterally in the occipital regions and in the right temperoparietal region. Although he improved after this second stroke-like episode he had a fixed neurological defecit comprising fluent dysphasia, cortical blindness, and a dense left hemiparesis. Muscle biopsy showed $10 \%$ ragged red fibres with the SDH stain which were all COX positive. He died 6 months after the initial presentation from bronchopneumonia. There was no family history of neurological disease.

PATIENT 3

A 32 year old woman developed normally until the age of 12 years when she had an acute episode of headache, photophobia, vomiting, and left arm focal motor fitting from which she fully recovered. She experienced two further similar episodes and after the second developed a dense left hemiplegia which subsequently resolved. There followed progressive cognitive decline, cerebellar ataxia, and complex partial seizures. Clinical examination when aged 29 disclosed a salt and pepper type retinopathy, cerebellar ataxia, mild spasticity in all four limbs, and intermittent dystonic posturing of her upper limbs as she walked. There was no limb weakness. Brain CT showed extensive low density areas involving both grey and white matter, most marked posteriorly. These were consistent with areas of infarction. Plasma lactate was raised at $4.9 \mathrm{mmol} / 1$. Muscle biopsy when aged 12 years showed 3\% ragged red fibres with the SDH stain which were all COX positive. There was no family history of neurological disease.

PATIENT 4

This right handed man was well until the age of 7 years when he developed episodic headaches with nausea, vomiting, and photophobia which were diagnosed to be common migraine. At the age of 9 years, in addition to the headaches he was having difficulty reading small print and was found to have bilateral optic atrophy. His headaches settled and he was otherwise well until the age of 34. At this age he became confused over the course of a day and was found to have a right homonymous hemianopia, nonfluent dysphasia, and a mild right hemiparesis. He made a complete recovery but at the age of 46 developed sudden onset bilateral visual loss with visual acuities reduced to $6 / 60$ in both eyes, and confusion. Brain scan showed areas of decreased attenuation in both occipital lobes consistent with areas of infarction. He subsequently developed generalised seizures and progressive cognitive decline. Examination at the age of 50 showed marked cognitive impairment with disorientation in time and place. $\mathrm{He}$ had bilateral optic atrophy and a salt and pepper type retinopathy. He had a broad based gait with limb incoordination and he exhibited generalised dystonic posturing. There was no clinical evidence of a myopathy. $\mathrm{He}$ had bilateral grasp reflexes and generalised hyperreflexia. Plasma lactate was raised at 4.4 $\mathrm{mmol} / 1$. Muscle biopsy showed 30\% ragged red fibres with the SDH stain which were all COX positive. Polarography of freshly isolated muscle mitochondria showed a defect of complex I. There was no family history of neurological disease.

\section{PATIENT 5}

This right handed man had normal motor and cognitive milestones but developed sensorineural deafness in his late teens. He developed cataracts in his 30 s requiring surgery. At the age of 45 he experienced headaches, vomiting, and increasing confusion over a period of three days culminating in a generalised seizure. Examination disclosed a fluent dysphasia, dyslexia, dysgraphia, and a right homonymous hemianopia. Brain CT disclosed a low density area in the left occipitoparietal region. He recovered fully but continued to have generalised seizures. At the age of 53 years he had a respiratory arrest after a generalised seizure and was ventilated. His conscious level remained impaired despite the absence of sedation. Examination showed rov-

Table 1 Clinical details and investigations in five patients with MELAS

\begin{tabular}{|c|c|c|c|c|c|c|}
\hline Patient & Age at first stroke & $\begin{array}{l}\text { Age last } \\
\text { examined }\end{array}$ & $L A$ & Additional features & Muscle histochemistry & $\begin{array}{l}\text { Family } \\
\text { history }\end{array}$ \\
\hline 1 & $23 \mathrm{y}(1)^{\star}$ & $30 \mathrm{y}$ & Yes & $\begin{array}{l}\text { EPC } \\
\text { Axonal neuropathy }\end{array}$ & $\begin{array}{l}10 \% \text { RRF } \\
\text { No COX-ve }\end{array}$ & None \\
\hline 2 & 52 y (2) & $52 \mathrm{y}$ & Yes & Deaf & $\begin{array}{l}10 \% \text { RRF } \\
\text { No COX-ve }\end{array}$ & None \\
\hline 3 & 12 y (3) & $32 \mathrm{y}$ & Yes & $\begin{array}{l}\text { Dystonia } \\
\text { Cerebellar ataxia } \\
\text { Spastic tetraraparesis } \\
\text { Dementia }\end{array}$ & $\begin{array}{l}3 \% \mathrm{RRF} \\
\text { No COX-ve }\end{array}$ & None \\
\hline 4 & $34 \mathrm{y}(2)$ & $50 \mathrm{y}$ & Yes & $\begin{array}{l}\text { Optic atrophy } \\
\text { Retinopathy } \\
\text { Cerebellar ataxia } \\
\text { Dystonia } \\
\text { Dementia }\end{array}$ & $\begin{array}{l}30 \% \text { RRF } \\
\text { No COX-ve }\end{array}$ & None \\
\hline 5 & 45 y (1) & $53 \mathrm{y}$ & Yes & $\begin{array}{l}\text { Cataracts } \\
\text { Deaf } \\
\text { Seizures } \\
\text { Leigh's disease on MRI }\end{array}$ & $\begin{array}{l}20 \% \text { RRF } \\
\text { No COX-ve }\end{array}$ & None \\
\hline
\end{tabular}

$\mathrm{LA}=$ lactic acidaemia (in plasma); $\mathrm{EPC}=$ epilepsia partialis continua; $\mathrm{RRF}=$ ragged red fibre with the succinate dehydrogenase method; $\mathrm{COX}=$ cytochrome $\mathrm{c}$ oxidase.

*Number in parentheses indicates the total number of stroke-like episodes. 
Table 2 Results of sequencing five patients with MELAS

\begin{tabular}{|c|c|c|c|}
\hline Patient & Nucleotide change & Gene & Reference \\
\hline \multirow[t]{7}{*}{1} & T5999C silent & COI & This report \\
\hline & A6047G silent & COI & This report \\
\hline & C7028T silent & COI & Ballinger $e t a l^{8}$ \\
\hline & T7705C silent & COII & This report \\
\hline & A8308G & tRNA Lys & Obayashi et al $l^{9}$ \\
\hline & A9383G silent & COIII & This report \\
\hline & A12308G & tRNA Leu(CUN) & Houshmand et al ${ }^{10}$ \\
\hline \multirow[t]{5}{*}{2} & G6734A silent & COI & This report \\
\hline & G8251A silent & COII & Ruvolo et $a l^{11}$ \\
\hline & G9947A silent & COIII & This report \\
\hline & $\mathrm{A} 10034 \mathrm{G}$ & tRNA Gly & Marzuki et $a l^{12}$ \\
\hline & $\mathrm{T} 15924 \mathrm{C}$ & tRNA Thr & Brown et $a l^{13}$ \\
\hline $3^{\star}$ & G583A & tRNA Phe & This report \\
\hline \multirow[t]{5}{*}{4} & 514CA deletion & D-loop & Ozawa et $a l^{14}$ \\
\hline & C7028T silent & $\mathrm{COI}$ & Ballinger $e t a l^{8}$ \\
\hline & A8860G & ATPase6 & Ballinger $e t a l^{\beta}$ \\
\hline & C9559G Phe to Arg & COIII & Kobayashi et al $l^{15}$ \\
\hline & $\mathrm{T} 10166 \mathrm{C}$ silent & ND4L & This report \\
\hline \multirow[t]{5}{*}{5} & G4580A silent & ND2 & Huoponen et $a l^{16}$ \\
\hline & A8982G silent & ATPase6 & This report \\
\hline & A8860G Thr to Ala & ATPase6 & Ballinger $e t a l^{8}$ \\
\hline & C9559G Phe to Arg & COIII & Kobayashi et $a l^{15}$ \\
\hline & $\mathrm{C} 15904 \mathrm{~T}$ & tRNA Thr & Houshmand et al ${ }^{10}$ \\
\hline
\end{tabular}

Silent indicates nucleotide change does not result in an amino acid substitution. The following abbreviations have been used: $\mathrm{G}=$ guanine; $\mathrm{C}=$ cytosine; $\mathrm{A}=$ adenine; $\mathrm{T}=$ thymine; $\mathrm{CO}=$ cytochrome c oxidase subunit gene; $\mathrm{tRNA}=$ transfer RNA gene; Lys=lysine; $\mathrm{Arg}=$ arginine; Thr=threonine; Phe=phenylalanine; Ala=alanine; Tryp=tryptophan; Gly=glycine; Leu=leucine; $\mathrm{ND}=$ nicotinamide adenine dehydrogenase subunit gene; ATPase=ATP synthase subunit gene; D-loop=displacement loop. ${ }^{\star}$ Pathogenic mutation.

ing eye movements and generalised stimulus sensitive myoclonus. His best motor response was flexion to pain. He had frequent focal motor seizures affecting his face and arms. Plasma and CSF lactate were raised at 8 and 7 $\mathrm{mmol} / 1$ respectively. Brain MRI showed gener-

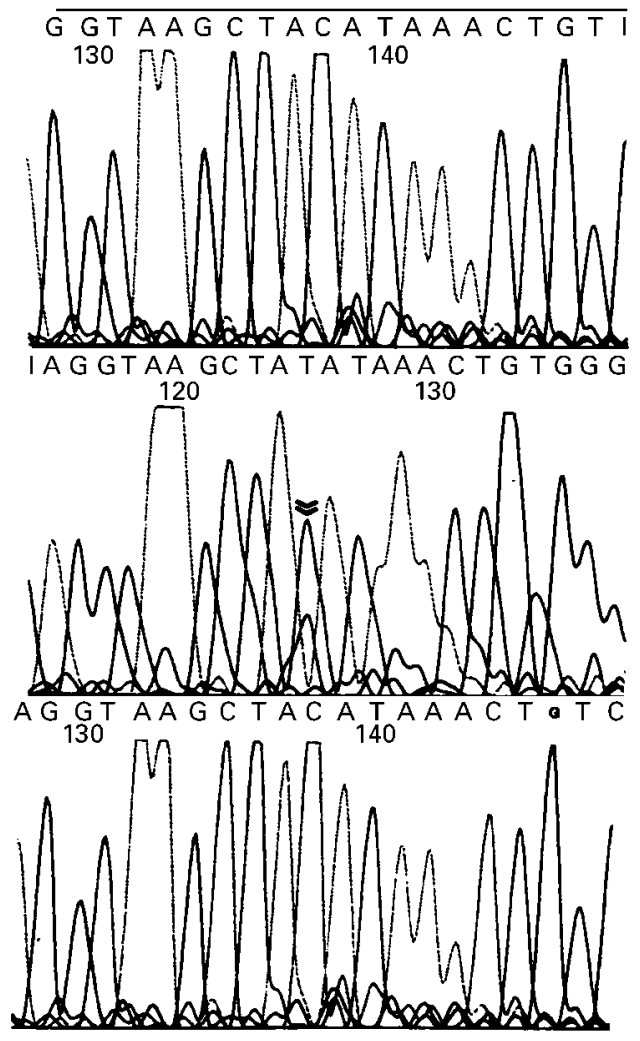

Figure 1 Chromatogram showing the heteroplasmic $G 583 A$ (C to $T$ on the antisense strand shown) transition in the mitochondrial $t R N A$ gene for phenylalanine. Top panel; normal control blood, middle panel; patient 3 muscle, bottom panel; patient 3 blood. Double arrow indicates the mutant nucleotide, which was only detected in the patient's muscle. alised atrophy and high signal areas in the paramedian regions extending from the medulla up to the medial thalamus, the appearance being consistent with Leigh's disease. Muscle biopsy showed 10\% ragged red fibres with the SDH stain. Most of the ragged red fibres had increased COX staining and there were no COX negative fibres. He was successfully removed from ventilation but his conscious level remained unchanged. He died 2 months later after a further respiratory arrest. There was no family history of neurological disease.

METHODS

The clinical details and results of mtDNA sequencing of the patients studied are summarised in tables 1 and 2. All initial sequencing and Southern blotting were performed on mtDNA extracted from muscle as this tissue is more likely to contain higher amounts of any mutation identified. ${ }^{6}$ When a change was identified in muscle, mtDNA from blood would then be analysed. Total DNA was extracted from muscle and blood and Southern blotting was performed using methods previously described. ${ }^{17}{ }^{18}$ Systematic sequencing of all mitochondrial transfer RNA and cytochrome c oxidase genes was undertaken using a Taq FS dye primer cycle sequencing kit and an automated DNA sequencer (Applied Biosystems Incorporated). The oligonucleotide primers used to amplify each region of mtDNA of interest were tagged with the M13 sequence at their 5 ' end. The primer sequences are available from the authors on request. The presence of the G583A point mutation was confirmed by a mismatch polymerase chain reacton (PCR) technique in which a restriction site for the endonuclease Cla-1 was introduced in the presence of the mutant nucleotide. The primers used for the mismatch PCR were, light strand: 371-390, and heavy strand: 603-584 TGCTTTGAGGAGGTAATCGA (mismatch nucleotides are shown in bold). This primer pair produce a $233 \mathrm{bp}$ product. This product is only cleaved into two fragments of 216 and $17 \mathrm{bp}$ if the mutant nucleotide is present. The conditions for the mismatch PCR were as follows: one cycle of $94^{\circ}$ for 3 minutes, followed by 30 cycles of $92^{\circ}$ for $30 \mathrm{~s}, 55^{\circ}$ for $30 \mathrm{~s}$, and $72^{\circ}$ for $30 \mathrm{~s}$, and finally one cycle of $72^{\circ}$ for $10 \mathrm{~min}$. Quantitation of the proportion of mutant mtDNA in the muscle of patient 3 was undertaken using a fluorescent method. Fluorescently labelled deoxynucleotide triphosphate was added to the last cycle of the mismatch PCR followed by digestion of the products with Cla-1. The products were then quantified using a 373 DNA sequencer and Gene-scan software (ABI).

\section{Results}

Southern blotting excluded a large scale rearrangement of mtDNA in all patients. Systematic sequencing of all tRNA genes and the three mitochondrially encoded COX genes was undertaken. In patients $1,2,4$, and 5 changes were identified compared with the 


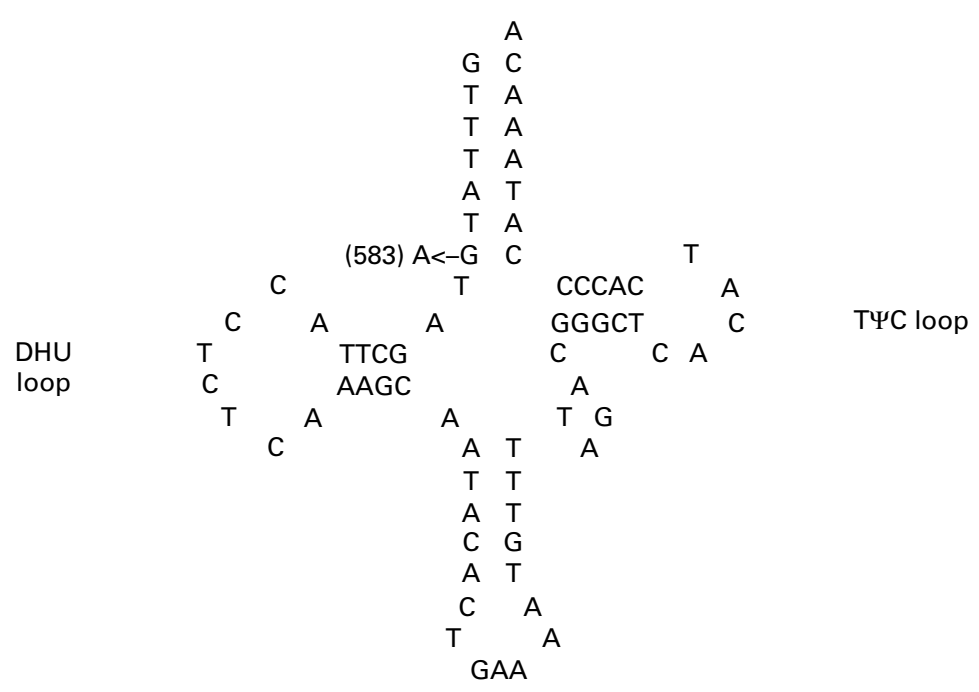

Anticodon loop

Figure 2 Theoretical two dimensional structure of the tRNA phenylalanine molecule illustrating the G583A transition mutation.

Anderson sequence ${ }^{19}$ and these are listed in table 2. None of these changes were likely to be of pathogenic relevance, either because they had previously been shown to occur in a control population or because they were silent not producing amino acid substitutions.

In patient 3 we identified a $G$ to $A$ transition at position 583 in the aminoacyl acceptor stem region of the tRNA gene for phenylalanine (figs 1 and 2). This mutation was identified in heteroplasmic form in muscle from the biopsy aged 12 years but was not detected in mtDNA extracted from the patient's blood sample taken at the age of 24 or from her mother's blood (fig 1). The proportion of the G583A mutation in the patients muscle was $58 \%$. Skin fibroblasts obtained form the patient did not harbour the mutation. The mother was well and had not had a muscle biopsy and the patient had no siblings. This mutation was not identified in mtDNA extracted from the blood of 100 healthy controls or from the muscle of a further 60 patients with ragged red fibres on muscle biopsy and varying mitochondrial disease phenotypes. Evolutionary comparison showed that a $\mathrm{G}$ nucleotide at position 583 is highly conserved. ${ }^{45}$

Table 3 Pathogenic MtDNA mutations associated with stroke-like episodes

\begin{tabular}{|c|c|c|}
\hline Mutation & Gene & Reference \\
\hline $\begin{array}{l}\text { G1642A } \\
\text { A3243G } \\
\text { A3252G } \\
\text { C3256T } \\
\text { A3260G } \\
\text { T3271C } \\
\text { T3291C } \\
\text { A5814G } \\
\text { T9957C } \\
\text { A8344G } \\
\text { T7512C } \\
\text { T8356C } \\
\text { Single deletion } \\
\text { Large scale tandem } \\
\text { duplication }\end{array}$ & $\begin{array}{l}\text { tRNA Valine } \\
\text { tRNA Leucine(UUR) } \\
\text { tRNA Leucine(UUR) } \\
\text { tRNA Leucine(UUR) } \\
\text { tRNA Leucine(UUR) } \\
\text { tRNA Leucine(UUR) } \\
\text { tRNA Leucine(UUR) } \\
\text { tRNA Cysteine } \\
\text { COX III } \\
\text { tRNA Lysine } \\
\text { tRNA Serine(UCN) } \\
\text { tRNA Lysine }\end{array}$ & 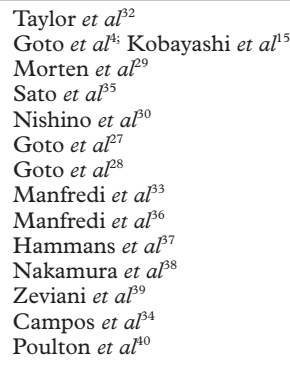 \\
\hline
\end{tabular}

\section{Discussion}

The acronym MELAS was introduced by Pavlakis $e t a l^{2}$ to characterise a specific group of patients who had the onset of symptoms between the ages of 3 and 11 years. They met the following criteria: normal early development, short stature, seizures and alternating hemiparesis, hemianopia, or cortical blindness. They all had ragged red fibres, lactic acidaemia, and parieto-occipital lucencies on CT. It was suggested that MELAS was a distinct clinical entity separable from MERRF (myoclonus epilepsy with ragged red fibres) and the Kearns-Sayre syndrome (KSS). Hirano et a ${ }^{20}$ proposed the following "invariant" criteria for a diagnosis of MELAS; (1) stroke-like episodes before the age of 40 years, (2) encephalopathy characterised by seizures, dementia, or both, and (3) lactic acidosis, ragged red fibres, or both. They suggested that the diagnosis is secure if there are at least two of the following; normal early development, recurrent headache, or recurrent vomiting. They did note that the distinction between MELAS and MERRF or KSS was not absolute. ${ }^{2}$ Many more cases of MELAS have now been described and it is clear that it is the clinical and radiological features of the stroke-like episodes themselves which are the cardinal features of the MELAS phenotype. ${ }^{21} 22$ The additional features represented in the acronym are variably present and there may be other features of respiratory chain disease which fall outside this strict definition. For example, lactic acidaemia and ragged red fibres, although often associated, are not always present. ${ }^{6}$ The age of onset is variable and cases in which the first stroke-like episode occurred long after the age of 40 have been reported..$^{23}$

The variation in natural history and clinical features of patients with strokes typical of those described in MELAS is well illustrated by the cases reported here (table 1). Two of the patients - 1 and 5-only had single events and were followed up for 7 and 8 years after the initial stroke respectively with no further events. Patients 4 and 5 illustrate that the stroke-like episodes can be many years apart. By contrast, patient 2 presented for the first time at the age of 52 years with a catastrophic illness leading to death in 6 months. In three patients $(2,4$, and 5) there were other clinical clues to suggest a mitochondrial respiratory chain disorder before the stroke-like episodes, namely preceding deafness, cataracts, or optic atrophy. It is notable that patient 5 evolved radiological and clinical features of Leigh's syndrome as well as MELAS. This combination has, to our knowledge, not been described before and highlights the overlap which can be seen between apparently distinct phenotypes of respiratory chain disease. $^{24}$

From a practical viewpoint these findings indicate that the diagnosis of MELAS (or perhaps more accurately a mitochondrial stroke) should be considered at any age in the presence of consistent clinical and imaging features. Such features should prompt a search for other clinical and historical features suggestive of a respiratory chain disorder which may be varied, subtle, or completely absent. The most 
useful investigations are a muscle biopsy, with appropriate staining, and mtDNA analysis. ${ }^{25}$

Most patients who exhibit features of the MELAS phenotype harbour a point mutation at position 3243 in the tRNA gene for leucine (UUR). ${ }^{6}$ Five further point mutations in the same tRNA gene have been described in association with MELAS. ${ }^{26-30}$ This has led to the suggestion that defects in this gene are specifically associated with this phenotype ${ }^{28}$ possibly by affecting RNA processing. ${ }^{31}$ However, subsequent studies have shown that defects elsewhere in the mitochondrial genome can also be associated with MELAS. These include point mutations in the tRNA genes for valine and cysteine and in the COX III gene and large scale rearrangements (table 3 ). ${ }^{32-34}$

The five patients described here had at least one typical stroke-like episode, COX positive ragged red fibres and lactic acidaemia and did not harbour a known mtDNA mutation. None of these patients harboured SDH positive blood vessels in muscle as have been described by others. ${ }^{41}$ In view of the association between tRNA gene defects and the presence of ragged red fibres ${ }^{42}$ and the finding that a mutation in a COX gene can associate with MELAS, ${ }^{36}$ we systematically analysed all tRNA and mitochondrial COX genes.

There are three lines of evidence to suggest that the new mutation we identified in patient 3 is pathogenic. Firstly, it is heteroplsmic, a feature generally associated with disease causing mutations rather than neutral polymorphisms. ${ }^{17}$ Secondly, it occurs at a highly conserved position within the tRNA gene for phenylalanine, suggesting functional importance of the wild type nucleotide at this position. Thirdly, we did not identify this mutation in a large panel of normal controls or in a further 60 patients with mitochondrial phenotypes who do not harbour any known mutations. Further confirmation of its pathogenicity requires functional studies and the identification of this mutation in additional kindreds. Unfortunately we were unable to perform functional studies as the mutation was not present in fibroblast cultures from this patient and myoblasts were unavailable. One other mutation in the tRNA gene for phenylalanine has been described in a patient with a myopathy and acute rhabdomyolysis indicating that different phenotypes may be associated with mutations in this gene. ${ }^{43}$ The absence of the 583 mutation from the mother's blood may be because the mutation arose de novo in the patient or because it has been lost from blood, possibly because of a selective disadvantage of blood cells harbouring the mutation. ${ }^{44}$ If the mother does harbour the mutation we presume it is in an insufficient amount to produce disease. It is notable that the patient did not have clinical evidence of a myopathy and only had mild histopathological changes in muscle. In view of her clinical presentation it is likely that she harbours higher amounts of this mutation in her brain.

The absence of mutations in the other four patients indicates that mitochondrial proliferation and formation of ragged red fibres are not necessarily associated with tRNA gene defects. It is likely that these patients harbour mutations elsewhere in the mitochondrial genome. The possibility that they harbour nuclear gene mutations cannot be excluded, although this seems less likely as ragged red fibres seem to associate with primary mitochondrial DNA defects.

In conclusion, we described the clinical and molecular genetic findings in five patients with stroke-like episodes typical of the MELAS phenotype. We provided evidence that a point mutation in the tRNA phenylalanine gene can associate with MELAS and that there is likely to be further genetic heterogeneity underlying the stroke-like episodes associated with mitochondrial respiratory chain disease. It is suggested that "mitochondrial stroke" may be a more clinically useful term.

We thank Professors Miller and Hodges and Drs Fish, Clarke, and Pilling for allowing us to study patients under their care. Support from the Medical Research Council of Great Britain (MGH) and the Muscular Dystrophy Group of Great Britain and Northern Ireland (IPN) is gratefully acknowledged.

1 Shapira Y, Cederbaum SD, Cancilla PA, et al. Familial poliodystrophy, mitochondrial myopathy and lactic acidaemia. Neurology 1975;25:614-21.

2 Pavlakis SG, Phillips PC, DiMauro S, et al. Mitochondrial myopathy, encephalopathy, lactic acidosis, and stroke like myopathy, encephalopathy, lactic acidosis, and stroke like episodes:

3 Shapira Y, Harel S, Russell A. Mitochondrial encephalomyopathies: a group of neuromuscular disorders with defects in

4 Ciafaloni E, Ricci E, Shanske S, et al. MELAS: clinical features, biochemistry, and molecular genetics. Ann Neurol 1992;31:391-8

5 Goto Y, Nonaka I, Horai S. A mutation in the tRNA Leu(UUR) gene associated with the MELAS subgroup of mitochondrial encephalomyopathies. Nature 1990;348: 651-3.

6 Hammans SR, Sweeney MG, Hanna $\mathrm{MG}$, et al. The mutation: a clinical and genetic study. Brain 1995;118:72134.

7 Servidei S. Mitochondrial encephalomyopathies; gene mutation. Neuromusc Disord 1997;7:12-17.

8 Ballinger SW, Schurr TG, Torroni A, et al. Southeast Asian mitochondrial DNA analysis reveals genetic continuity of mitochondrial DNA analysis reveals genetic continuity of
ancient mongoloid migrations. Genetics 1992;130:139-52.

9 Obayashi T, Hattori K, Sugiyama ST, et al. Point mutations in mitochondrial DNA in patients with hypertrophic in mitochondrial DNA in patients with hype
cardiomyopathy. Am Heart f 1992;124:1263-9.

10 Houshmand $M$, Larsson NG, Holme E, et al. Automated sequencing of mitochondrial tRNA genes in patients with mitochondrial encephalomyopathy. Biochem Biophys Acta 1994;1226:49-55.

11 Ruvolo M, Zehr S, von Dornum M, et al. Mitochondrial COII sequences and modern human origins. Mol Biol Evol 1993;10:1115-35.

12 Marzuki S, Noer AS, Letrit P, et al. Normal variants of human mitochondrial DNA and translation products: the building of a reference data base. Genetics 1991;88:139-45.

13 Brown MD, Torroni A, Shoffner JM, et al. Mitochondrial tRNA Thr mutations and lethal infantile mitochondrial myopathy. Am f Hum Genet 1992;51:446-7.

14 Ozawa $T$, Tanaka $M$, Ino $H$, et al. Distinct clustering of point mutations in mitochondrial DNA among patients point mutations in mitochondrial DNA among patients son's disease. Biochem Biophys Res Commun 1991;176:93846.

15 Kobayashi Y, Momoi MY, Tominaga K, et al. Respirationdeficient cells are caused by a single point mutation in the mitochondrial tRNALeu(UUR) gene in mitochondrial myopathy, encephalopthy, lactic acidosis and stroke like episodes (MELAS). Am f Hum Genet 1991;49:590-9.

16 Huoponen K, Lamminen T, Juvonen V, et al. The spectrum of mitochondrial DNA mutations in families with Leber hereditary optic neuroretinopathy. Hum Genet 1993;92: 379-84

17 Hanna MG, Nelson I, Sweeney MG, et al. Congenital myopathy, adult onset myopathy and diabetes mellitus: different phenotypic associations of a new heteroplasmic mitochondrial tRNA glutamic acid mutation. Am 7 Hum Genet $1995 ; 56: 1025-30$

18 Holt IJ, Harding AE, Morgan-Hughes JA. Deletions of muscle mitochondrial DNA in patients with mitochondrial muscle mitochondrial DNA in patients

19 Anderson S, Bankier BG, de Bruijn MH, et al. Sequence and organisation of the human mitochondrial genome. Nature 1981;290:457-65. 
20 Hirano M, Ricci E, Koenigsberger MR, et al. MELAS: an original case and clinical criteria for diagnosis. Neuromusc original case and clinical
Disord $1992 ; 2: 125-35$

21 Matthews M, Tampieri D, Berkovic SF, et al. Magnetic resonance imaging shows specific abnormalities in the MELAS syndrome. Neurology 1991;41:1043-6.

22 Rosen I, Phillips S, Enzmann D. Magnetic resonance imag-
ing in MELAS syndrome. Neuroradiology 1990;32:168-71.

Hanna MG, Vaughan JR, Silburn PA, et al. Two unusual clinical presentations of the mitochondrial DNA A3243G point mutation in adult neurological practice. $7 \mathrm{Neurol}$ Neurosurg Psychaitry 1997;62:544-6.

24 Morgan-Hughes JA. Mitochondrial diseases. In: Engel AG, Franzini-Armstrong C, eds. Myology. 2nd ed. New York: McGraw-Hill, 1994:1610-60.

25 Jackson MJ, Schaefer JA, Johnson MA, et al. Presentation and clinical investigation of mitochondrial respiratory chain disease: a study of 51 patients. Brain 1995;118:339chain 57 .

26 Goto Y, Nonaka I, Horai S. A new mtDNA mutation associated with mitochondrial myopathy, encephalopathy, lactic
acidosis, and stroke like episodes (MELAS). Biochem acidosis, and stroke like episode

27 Goto Y, Tojo M, Tohyama J. A novel point mutation in the mitochondrial tRNA Leu(UUR) gene in a family with mitochondrial myopathy. Ann Neurol 1992;31:672-4.

28 Goto Y, Tsugane K, Tanabe Y, et al. A new point mutation at nucleotide pair 3291 of the mitochondrial tRNA ${ }^{\text {Leu(UUR }}$ gene in a patient with mitochondrial myopathy, encephalopathy, lactic acidosis, and stroke like episodes Biochem Biophys Res Comm 1994;202:1624-30.

29 Morten K, Cooper M, Brown GK, et al. A new point mutation associated with mitochondrial encephalopathy. Hum Molec Genet 1993;2:2081-7.

30 Nishino I, Komatsu M, Kodama S, et al. The 3260 mutation in mitochondrial DNA can cause mitochondrial myopathy, encephalopathy, lactic acidosis, and stroke like episodes (MELAS). Muscle Nerve 1996;19:1603-4.

31 Kaufmann P, Koga Y, Shanske S, et al. Mitochondrial DNA and RNA processing in MELAS. Ann Neurol 1996;40:172and $\mathrm{RN}$

32 Taylor RW, Chinnery PF, Haldane F, et al. MELAS associated with a mutation in the valine transfer RNA gene of mitochondrial DNA. Ann Neurol 1996;40:459-62.

33 Manfredi G, Schon EA, Bonilla E, et al. Identification of a mutation in the mitochondrial tRNA ${ }^{\text {Cys }}$ gene associated with mitochondrial encephalomyopathy. Hum Mutat 1996; $7: 158-63$.

34 Campos Y, Garcia-Silva T, Barrionuevo CR, et al.
Mitochondria. DNA deletion in a patient with mitochondrial myopathy, lactic acidosis, and stroke-like episodes drial myopathy, lactic acidosis, and stroke-like episodes 1995;13:69-72.

35 Sato W, Hayasaka K, Shoji Y, et al. A mitochondrial tRNA (Leu (UUR) ) mutation at 3256 associated with mitochondrial myopathy, encephalopathy, lactic acidosis, and strokeike episodes (MELAS). Biochem Mol Biol Int 1994;33: 1055-61.

36 Manfredi G, Schon EA, Moraes CT, et al. A new mutation associated with MELAS is located in a mitochondrial DNA polypeptide-coding gene. Neuromusc Disord 1995;5:391-8.

37 Hammans SR, Sweeney MG, Brockington M, et al. The mitochondrial DNA transfer $\mathrm{RNA}^{\mathrm{Lys}} \mathrm{A}->\mathrm{G}^{(8344)}$ mutation and the syndrome of myoclonic epilepsy with ragged red fibres (MERRF): relationship of clinical phenotype to proportion of mutant mitochondrial DNA. Brain 1993;116: 617-32.

38 Nakamura $M$, Nakano S, Goto $Y$, et al. A novel point mutation in mitochondrial tRNA ${ }^{\text {Ser(UCN) }}$ gene detected in a family with MERRF/MELAS overlap syndrome. Biochem Biophys Res Commun 1995;214:86-93.

39 Zeviani M, Muntoni F, Savarese N, et al. A MERRF/ MELAS overlap syndrome with a new point mutation in MELAS overlap syndrome with a new point mutation in the mitoc.

40 Poulton J, Deadman ME, Gardiner RM. Duplication of mitochondrial DNA in mitochondrial myopathies. Lancet 1989;i:236-40.

41 Hasegawa H, Matsuoka T, Goto Y, et al. Strongly succinate dehydrogenase-reactive blood vessels in muscles from patients with mitochondrial myopathy, encephalopathy, actic acidosis and stroke like episodes. Ann Neurol 1991;29:601-5.

42 Moraes CT, Ricci E, Bonilla E, et al. The mitochondrial tRNA $^{\text {Leu(UUR) }}$ mutation in mitochondrial encephalomyopathy, lactic acidosis, and stroke like episodes (MELAS): genetic, biochemical and morphological correlations in genetic, biochemical and morphological correlation

43 Chinnery PF, Johnson MA, Taylor RW, et al. A novel mitochondrial tRNA phenylalanine mutation presenting with acute rhabdomyolosis. Ann Neurol 1997;41:408-10.

44 Nelson I, Hanna MG. Alsaniarni N, et al A new mitochonNelson I, Hanna MG, Alsanjarni N, et al. A new mitochon-
drial DNA mutation associated with progressive dementia and chorea: a clinical, pathological and molecular genetic study. Ann Neurol 1995;37:400-3.

45 Sprinzl M, Hartmann T, Weber J, et al. Compilation of tRNA sequences and sequences of tRNA genes. Nucleic Acids Res 1989;17(suppl):r1-172. 